\title{
Clipboard
}

\section{Eppin: A candidate male contraceptive vaccine?}

Until now, efforts towards developing a hormone-based male contraceptive vaccine have met with little success. Since the early 1990s, reproductive biologists have focused their interests on sperm-specific molecules such as lactate dehydrogenase isoform 4 (O'Hearn et al 1995), RSA-1, human SP17, Tcle-1, $\beta \mathrm{H} 2 \mathrm{O}$ and SP10 (Harrison and Rosenfield 1996), but none of these studies have come up with a successful contraceptive agent as yet. A major reason for the lack of success has been the absence of a sustained and effective response in all subjects.

Eppin (epididymis protease inhibitor), a recently identified and characterized 'male-only' molecule from the testis, appears to be promising in this context. Testicular sperms cannot fertilize eggs until they pass through the epididymis, an anatomical structure that is juxtaposed posterior to the testis. There, via processes that are not yet completely understood, they become mature, meaning competent to fertilize. Eppin is a 133 amino acid protein that is believed, on the basis of its sequence, to function as a serine protease inhibitor and is secreted by the epididymidis in an androgen-dependent manner; it is found on the surface of spermatozoa and is likely to be important for sperm maturation (Richardson et al 2001). Therefore it appeared reasonable to propose that neutralization of Eppin would interfere with the process of sperm maturation and eventually negatively affect fertilization. In a recent study, O'Rand et al (2004) have investigated the potential of this method of immuno-contraception.

The researchers immunized 9 male monkeys (Macaca radiata) of proven fertility with human recombinant Eppin every three weeks and monitored antibodies in circulation as well as in the epididymal fluid. Of these, 7 animals developed Eppin-specific high titre antibodies. Each of these 7 monkeys was then cohabitated with at least three female monkeys, also of proven fertility, and the reproductive outcomes monitored. None of the immunized monkeys successfully impregnated female monkeys, whereas 4 of the 6 control monkeys - which had been immunized with the adjuvant alone - did. More importantly, as the antibody titres waned with time, that is, $\sim 450$ days after the last immunization with Eppin, the fertilizing capacities of 5 out of the 7 male monkeys were restored. This showed that the 'period of infertility' in the male monkeys was reversible.

However, one thing to note is that not all the monkeys recruited for the study induced high titre antibodies to Eppin - not surprisingly, as the response to any immunogen varies from individual to individual. However, this might turn out to be a stumbling block when it comes to thinking of Eppin as a possible immuno-contraceptive in humans.

For this reason, Eppin cannot be called a successful candidate vaccine for the control of male fertility as of now. Nevertheless, it holds out promise: studies can be geared towards enhancing the immune response to the molecule. In any case, once the mechanism of action of Eppin is elucidated at the molecular level, it will provide leads to the identification of small molecules (including peptides) that can effectively inhibit Eppin activity. This approach might be more dependable than the generation of anti-Eppin antibodies in every individual desiring incapacitation of his sperms.

\section{References}

Harrison P F and Rosenfield A (eds) 1996 Contraceptive technology and the state of science: New horizons (Washington DC: National Academy Press) pp 125-165

O'Hearn P, Bambra C, Isahakia M and Goldberg E 1995 Reversible contraception in female baboons immunized with a synthetic epitope of sperm specific LDH; Biol. Reprod. 52 331-339

O'Rand M G, Widgren E E, Sivashanmugam P, Richardson R T, Hall S H, French F S, VandeVoort C A, Ramachandra S G, Ramesh V and Jagannadha Rao A 2004 Reversible imunocontraception in male monkeys immunized with Eppin; Science 306 1189-1190 
Richardson R T, Sivashanmugam P, Hall S H, Hamil K G, Moore P A, Rul S M, French F S and O'Rand M 2001 Cloning and sequencing of human Eppin: a novel family of protease inhibitors expressed in the epididymis and testis; Gene 270 93-102

ANJALI KARANDE

Department of Biochemistry, Indian Institute of Science,

Bangalore 560 012, India

(Email:anjali@biochem.iisc.ernet.in)

ePublication: 29 November 2004 